\title{
Outcomes and component-positioning in total knee arthroplasty may be comparable between supervised trained surgeons and their supervisor
}

\author{
Kazumi Goto* ${ }^{*}$, Yozo Katsuragawa and Yoshinari Miyamoto
}

\begin{abstract}
Purpose: There are concerns that malalignment in total knee arthroplasty (TKA) occurs with less experienced surgeons. This study investigates the influence of surgical experience on TKA outcomes.

Materials and methods: Nineteen patients (38 knees) who underwent bilateral TKA between 2011 and 2015 were included. A supervisor performed knee replacements associated with lower Knee Society Scores (KSS); trainee surgeons operated on the other knee. Knees were categorized into two groups: operations by the supervisor (group S) versus operations by trainee surgeons (group T). Range of motion (ROM), KSS, operative time, hip-knee-ankle angle, and femoral and tibial component angle were evaluated.

Results: The mean operative time was $92.5 \mathrm{~min}$ in group $\mathrm{S}$ and $124.2 \mathrm{~min}$ in group $T(p<0.01)$. The mean postoperative maximal flexion was $113.2^{\circ}$ in group $S$ and $114.2^{\circ}$ in group $T$ (not significant). The mean postoperative KSS was 92.9 in group S and 93.9 in group T (not significant). No significant differences between groups in terms of proportion of inliers for the hip-knee-ankle angle, femoral component angle, or tibial component angle were observed.
\end{abstract}

Conclusions: Although operative time was significantly longer for trainee surgeons versus the supervisor, no significant differences in ROM, KSS, or component positioning between supervisor and trainee surgeons were observed.

Level of evidence: IV (retrospective case series design).

Keywords: Simultaneous bilateral total knee arthroplasty, Outcome, Alignment, Surgical experience

\section{Introduction}

Total knee arthroplasty (TKA) is one of the most commonly performed elective procedures worldwide with excellent long-term outcomes [1, 2]. Patient survival is $99 \%$ after 1 year and 84\% after 10 years [3]. Furthermore, TKA is cost-effective in the management of end-stage knee osteoarthritis [4]. However, approximately $20 \%$ of primary TKA patients are not satisfied with their outcome [5]. Outcomes of TKA result from the confluence of various factors, including hospital and surgeon procedure volume

\footnotetext{
* Correspondence: kazumi@kgorthop.com

Department of Orthopedic Surgery, Center Hospital of the National Center for Global Health and Medicine, Toyama 1-21-1, Shinjuku-ku, Tokyo 162-8655, Japan
}

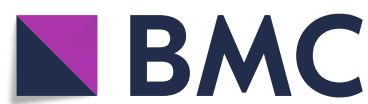

Part of Springer Nature
[6-8]. Several studies have suggested that surgeon experience affects the outcomes of arthroplasty [8-11]. Wilson et al. [8] demonstrated that primary TKA was a relatively low-risk surgical procedure in terms of surgical, medical, and wound complications and surgical readmissions at their institution. However, the risk of wound complications was much higher in patients operated on by junior trainees than in those operated on by more experienced surgeons. On the other hand, a study of 673 TKAs showed no difference between consultant and trainee surgeons in terms of component alignment [11].

However, it is unclear how much patient-dependent variables, for example, muscle strength, anatomical characteristics, or pain sensitivity influenced the results of

(c) The Author(s). 2020 Open Access This article is distributed under the terms of the Creative Commons Attribution 4.0 International License (http://creativecommons.org/licenses/by/4.0/), which permits unrestricted use, distribution, and reproduction in any medium, provided you give appropriate credit to the original author(s) and the source, provide a link to the Creative Commons license, and indicate if changes were made. The Creative Commons Public Domain Dedication waiver (http://creativecommons.org/publicdomain/zero/1.0/) applies to the data made available in this article, unless otherwise stated. 
these previous studies since they compared outcomes between patients. We thought it might be possible to minimize the influence of individual factors by comparing the results between the right and left knee in simultaneous TKA.

The purpose of this study was to investigate the potential differences in outcomes and component positioning between a supervisor and trainee surgeons in simultaneous TKA. The hypothesis was that the knee operated on by a less experienced surgeon would show neither poorer outcomes nor increased malpositioning of components than the knee operated on by a more experienced surgeon.

\section{Materials and methods}

This study used a retrospective case series design (Level IV evidence), approved by the institutional review board. The files of 77 patients (154 knees) who underwent simultaneous bilateral primary TKA at our institution between December 2011 and July 2015 were reviewed. Inclusion criteria for the study were as follows: primary simultaneous bilateral TKA using the same cruciateretaining TKA system (Vanguard ${ }^{\circ}$ CR, Zimmer Biomet Inc., Warsaw, IN, USA) and that one knee arthroplasty was performed by the supervisor and the other arthroplasty was performed by a trainee. Exclusion criteria were as follows: follow-up less than 1 year, history of revision TKA surgery, prior osteotomies around the knee, and previous septic arthritis.

Based on these criteria, 58 patients (116 knees) had to be excluded. Complete preoperative and postoperative clinical data were available for 19 patients (38 knees). The mean patient age was $76.8 \pm 5.7$ years (range 64-86 years) and 17 of the patients were female. Patient characteristics are shown in detail in Table 1.

All surgeries were performed under general anesthesia. A minimally invasive, mini-midvastus approach was used, and the patella was preserved. The femoral components were fixed without cement using conventional intramedullary devices. The tibial components were fixed with cement using conventional extramedullary devices. In both groups, the proximal tibia was resected first, followed by femoral resection. The aim of femoral resection was to be paralleled to the surgical epicondylar axis, with secondary referencing to the posterior condylar axis and the Whiteside line [12]. The rotation of the tibial component was determined by combining Akagi's line [13] with the self-adjusting technique [14]. The goal of these procedures was to restore a neutral hip-knee-ankle angle (HKA) with a neutral femoral component and the tibial component angles in the coronal plane. The first replacement was performed on the knee that had a lower Knee Score (KS) on the Knee Society Score (KSS) by a supervisor who had experience of over 1000 TKAs. The same supervisor performed the procedure in all 19 patients. The other knee was then operated on by trainee surgeons who had performed fewer than 20 TKAs. The supervisor was present during all trainee procedures.

The knees were consecutively divided into two groups: group $\mathrm{S}$ with knees operated on by the supervisor and group $\mathrm{T}$ with knees operated on by a trainee surgeon. Clinical and radiographic assessments were performed preoperatively and at 6 weeks, 3 months, and 1 year postoperatively. The osteoarthritis (OA) grade (KellgrenLawrence classification) of knees was defined on preoperative X-ray films. Clinical outcome measures included range of motion (ROM) and KSS. Operative time was recorded in minutes from skin incision to wound closure. The femoral-tibial angle (FTA), HKA, and the orientation of the two components were determined based on long-leg weight-bearing radiographs 6 weeks postoperatively. The coronal alignment of the entire lower limb was assessed using the HKA. The measured angle between the coronal femoral mechanical axis and the femoral component was defined as the femoral component angle (FCA). The measured angle between the coronal tibial mechanical axis and a line through the proximal aspect of the tibial component was defined as the tibial component angle (TCA; Fig. 1). For HKA and individual component positioning, both $2^{\circ}$ and $3^{\circ}$ cutoff values were used for the evaluation of inliers. The varus angle was considered as a positive value, and the valgus angle was considered as a negative value. Radiographic digital measurements were performed twice at two different points in time by a single author (KG). This author was blinded as to who had operated on the examined knee. The intra-observer error was less than

Table 1 Demographic data and preoperative characteristics

\begin{tabular}{llll}
\hline & Group S & Group T & $P$ value \\
\hline Preoperative maximal flexion (degrees) & $115.3 \pm 20.0$ & $118.9 \pm 16.3$ & 0.80 \\
Preoperative Knee Score & $35.1 \pm 15.0$ & $46.1 \pm 11.7$ & 0.022 \\
Preoperative Function Score & $42.4 \pm 22.3$ & & - \\
Preoperative FTA (degrees) & $187.8 \pm 6.3$ & $184.7 \pm 3.6$ & 0.14 \\
Preoperative HKA (degrees) & $166.2 \pm 6.4$ & $169.2 \pm 3.9$ & 0.14 \\
\hline
\end{tabular}

HKA hip-knee-ankle angle, FTA femoral-tibial angle 


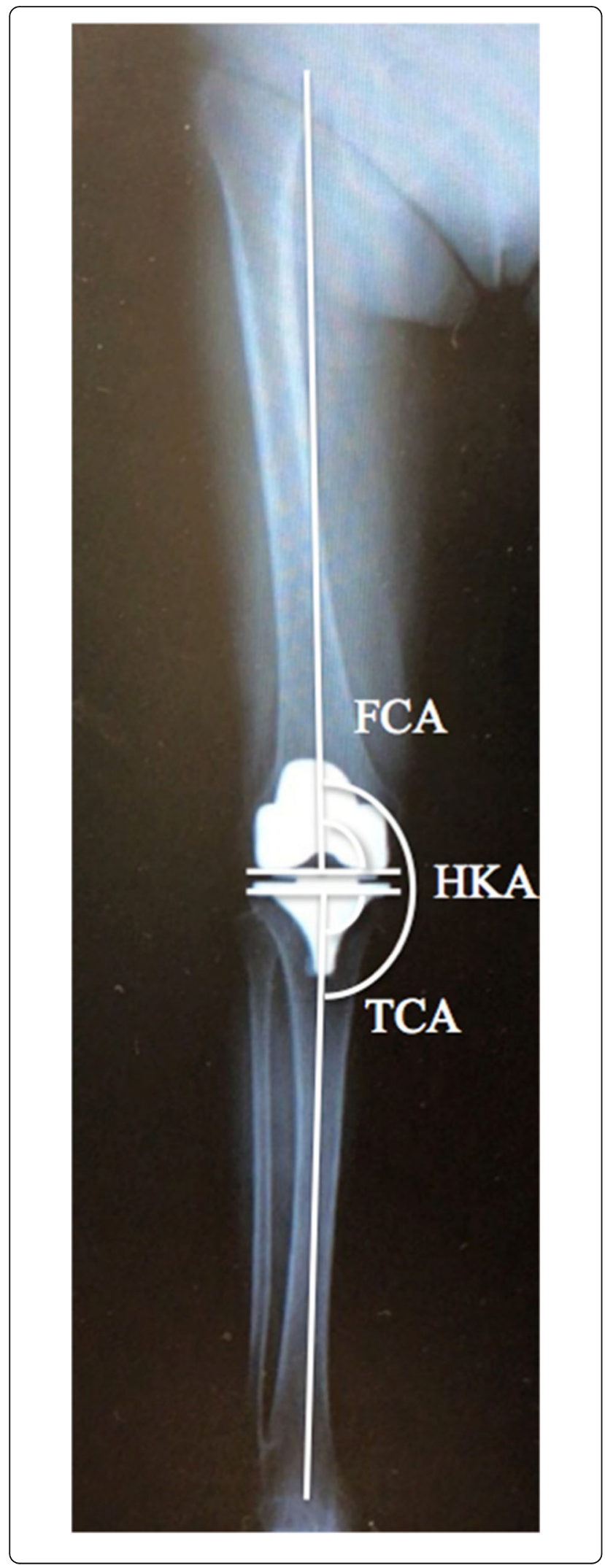

Fig. 1 Radiograph of the postoperative component alignment in the coronal plane. HKA was measured as the white line. FTA was measured as the angle between the femoral shaft axis and tibial shaft axis. FCA femoral coronal angle, FTA femoral-tibial angle, HKA hip-knee-ankle angle, TCA tibial coronal angle

$2^{\circ}$ for any measurement. The occurrence of severe complications (wound dehiscence, septic arthritis, and periprosthetic fracture) during the post-operative period was also recorded.

Preoperative demographic characteristics, operative time, ROM, and KSS were analyzed using a non-parametric test (Mann-Whitney U). Fisher's exact test was used to assess differences in the number of inliers of component positioning and alignment between subgroups. A $p$ value $<0.01$ was considered statistically significant. All statistical analyses were performed using the free $\mathrm{R}$ software (version 3.2.1; R Development Core Team).

\section{Results}

There were no severe postoperative complications (wound dehiscence, septic arthritis, or periprosthetic fracture) during the follow-up. The preoperative OA grade was not significantly different between the groups $(p=0.78)$. The mean preoperative KSS was $36.1 \pm 15.0$ in group $\mathrm{S}$ and $46.1 \pm 11.7$ in group $\mathrm{T}(p<0.01)$. The preoperative KSS was significantly lower in group $S$ than in group $\mathrm{T}$ (Table 1). The mean preoperative maximal extension was $-10.3 \pm 5.5^{\circ}$ in group $S$ and $-7.9 \pm 4.1^{\circ}$ in group T. The mean preoperative ROM, FTA, and HKA were not significantly different between the two groups (Table 1). The mean operative time was $92.5 \pm 13.6 \mathrm{~min}$ in group $\mathrm{S}$ and $124.2 \pm 12.2 \mathrm{~min}$ in group $\mathrm{T}$, which was a statistically significant difference (Table 2 ).

The mean postoperative maximal extension was $1.8 \pm 4.9^{\circ}$ in group $\mathrm{S}$ and $-1.3 \pm 4.5^{\circ}$ in group $\mathrm{T}$. The mean postoperative maximal flexion was $113.2 \pm 15.7^{\circ}$ in group $\mathrm{S}$ and $114.2 \pm 14.2^{\circ}$ in group $\mathrm{T}$ (Table 2). The mean postoperative KSS was $92.9 \pm 9.4$ in group $\mathrm{S}$ and $93.9 \pm 5.8$ in group $\mathrm{T}$. The overall mean function score (FS) of the KSS improved from $42.4 \pm 22.3$ to $69.5 \pm 10.6$ postoperatively.

The postoperative component alignment in the coronal plane in both groups is shown in Table 3. The mean postoperative FTA was $176.1 \pm 2.8^{\circ}$ in group $\mathrm{S}$ and $173.0 \pm 3.0^{\circ}$ in group $\mathrm{T}(p<0.01)$. The mean

Table 2 Postoperative characteristics

\begin{tabular}{llll}
\hline & Group S & Group T & $P$ value \\
\hline Operative time (min) & $92.5 \pm 13.6$ & $124.2 \pm 12.2$ & 0.00000037 \\
Postoperative maximal flexion & $113.2 \pm 15.7$ & $114.2 \pm 14.3$ & 0.84 \\
Postoperative Knee Score & $92.9 \pm 9.4$ & $93.9 \pm 5.8$ & 0.70 \\
Postoperative function score & $69.5 \pm 10.6$ & & - \\
\hline
\end{tabular}


Table 3 Overall and individual component alignment in the coronal planes

\begin{tabular}{lllll}
\hline & FTA & HKA & FCA & TCA \\
\hline Group S & $176.1 \pm 2.8$ & $178.0 \pm 2.8$ & $91.6 \pm 5.2$ & $89.1 \pm 2.1$ \\
Group T & $173.0 \pm 3.0$ & $180.7 \pm 2.7$ & $90.4 \pm 1.9$ & $91.2 \pm 1.4$ \\
$P$ value & 0.0026 & 0.0047 & 0.092 & 0.0022
\end{tabular}

FTA femoral-tibial angle, HKA hip-knee-ankle angle, FCA femoral coronal angle, TCA tibial coronal angle

postoperative HKA was $178.0 \pm 2.8^{\circ}$ in group $\mathrm{S}$ and $180.7 \pm 2.7^{\circ}$ in group $\mathrm{T}(p<0.01)$. The alignment of the knee was more likely to be varus in group $S$ than in group $\mathrm{T}$ (Table 3 ).

In the coronal plane, there was no significant difference between the two groups regarding the proportion of inliers at $2^{\circ}$ or $3^{\circ}$ cutoff values for HKA, FCA, and TCA (Table 4).

\section{Discussion}

The most important finding of this study is that operative time was significantly longer in the trainee surgeon group; however, there were no significant differences in ROM, KSS, or component positioning between the supervisor and trainee surgeons. An unexpected finding was that the postoperative HKA was closer to neutral with trainee surgeons, which had been set as a goal for these surgeries, than the experienced surgeon.

Several studies have demonstrated that higher surgical and hospital volumes are associated with more favorable patient outcomes [8-10]. Patients operated on by lowvolume surgeons were more likely to report an inability to flex the knee to $90^{\circ}$ and to achieve full extension at the 2-year follow-up [12]. Highly skilled surgeons achieve good outcomes and, as they gain experience, they become better in selecting patients more suitable for surgery [10]. Training and education in the treatment of a specific condition should therefore lead to improved outcomes [15]. However, it seems that TKA mid-term survival does not depend on surgeon volume [16]. Moreover, no association between surgeon volume and 1- and 3 -year revision rates has been observed [17, 18]. It appears that the association between surgeon experience and clinical outcomes remains contentious.

Wilson et al. [8] also compared the surgical outcomes of 2272 total hip arthroplasties and 2646 TKAs performed

Table 4 The percentage of inliers in the coronal planes

\begin{tabular}{llll}
\hline & HKA & FCA & TCA \\
& \multicolumn{1}{l}{ Percentage inliers } & within $3^{\circ}\left(\right.$ within $\left.2^{\circ}\right)$ & \\
\hline Group S & $60.0(35.0)$ & $85.0(75.0)$ & $90.0(75.0)$ \\
Group T & $90.0(75.0)$ & $85(75.0)$ & $100.0(75.0)$ \\
$P$ value & $0.65(0.11)$ & $1.00(1.00)$ & $0.49(1.00)$ \\
\hline
\end{tabular}

HKA hip-knee-ankle angle, FCA femoral coronal angle, TCA tibial coronal angle by trainees and consultants. Their research demonstrated that there were no associations between complications, transfusion rate, or surgical readmissions. Furthermore, they found that whether a consultant or trainee had performed the procedure had no significant effect on outcomes. Other similar studies have reported that outcomes may be comparable between trainees and supervisors when operations are performed under supervision or using a navigation system [19-22]. The major difference in our study was that we compared the outcomes of more and less experienced surgeons in the same patients without the use of a navigation system. The advantage of this approach is that patient-dependent variables (for example, pain sensitivity, muscle strength, bone quality) are eliminated. Traditional parallel group studies may have a potential for bias. There were no significant differences in the preoperative KSS between the two groups, although it is difficult to ignore the influence of this gap in preoperative knee conditions.

Several studies have reported that accurate component positioning improves functional outcomes [23-25]. Huang et al. [26] reported that accurate coronal alignment of total knee prostheses (to within $3^{\circ}$ of neutral) resulted in better function and better quality of life up to 5 years postoperatively. A study by Mahaluxmivala et al. [11] compared component positioning between consultant and trainee surgeons in 674 TKAs. They found that there was a trend toward more accurate component positioning by consultants. However, the alignment was not significantly different. In our study, the rates of outliers were not significantly different between the two groups, but the HKA was closer to neutral in the trainee group. One reason for this might be that operative time in the trainee group was significantly longer, possibly for component positioning and alignment evaluation under the direct supervision of the supervisor. Consequently, there is a possibility that results might be different if surgery was performed by the trainee alone without such supervision.

This study has several limitations that should be acknowledged. First, the study had a selection bias. Trainee surgeons were more likely to operate on easier cases whereas the supervisor operated on the more severely degenerated cases. In fact, the knees operated on by the supervisor had slightly lower preoperative KSS. Therefore, this may have the effect of reducing the difference in outcomes between the two groups. In addition, it is possible that, if a patient is not satisfied with one knee, it will affect the self-reported outcome of the other knee as well. Second, only one supervisor performed all the operations in this study. There is, therefore, a possibility that the surgical technique of this supervisor was suboptimal. However, the mean postoperative KSS was over 90 in both groups. Third, all trainee surgeries were 
performed under the direct supervision of this supervisor. Hence, this study was not a comparison of surgical outcomes between a supervisor and trainees when operating independently. Fourth, the long-term results in our study are unknown, and a longer follow-up is required to confirm findings. Finally, the number of patients was very small, and the results might vary from those of studies with larger sample sizes, especially for the comparison of complications. This is the biggest limitation of this study; thus, further large-scale studies are required for better comparisons.

Despite these limitations, however, no prior study in the orthopedic literature has compared the outcomes between a supervisor and trainee surgeons in simultaneous TKA. Our results are a good reference for educational institutions as it eliminated patient-related individual factors influencing outcomes by allowing one patient to serve as the experiment and the control.

\section{Conclusions}

Although operative time was significantly longer for trainee surgeons versus the supervisor, no significant differences in ROM, KSS, or component-positioning were observed between the supervisor and trainee surgeons.

\section{Abbreviations}

FS: Function score; FTA: Femoral-tibial angle; HKA: Hip-knee-ankle angle; KS: Knee Score; ROM: Range of motion; TKA: Total knee arthroplasty

\section{Acknowledgements}

We would like to thank Editage (http://www.editage.com) for editing and reviewing this manuscript for English language.

\begin{abstract}
Authors' contributions
GK and KY conceived the presented idea. GK developed the theory and performed the computations. GK and MY verified the analytical methods. KY encouraged GK to investigate this study and supervised the findings of this work. GK designed the study and wrote the initial draft of the manuscript. MY contributed to the analysis and interpretation of data and assisted in the preparation of the manuscript. All other authors have contributed to data collection, interpretation, and critically reviewed the manuscript. KY conceived the study and was in charge of the overall direction and planning. All authors approved the final version of the manuscript and agree to be accountable for all aspects of the work in ensuring that questions related to the accuracy or integrity of any part of the work are appropriately investigated and resolved.
\end{abstract}

\section{Authors' information}

K.Y. is a specialist of knee arthroplasty with experience of over 2000TKAs.

\section{Funding}

This research did not receive any specific grant from funding agencies in the public, commercial, or not-for-profit sectors.

\section{Availability of data and materials}

The datasets from and/or analyzed during the current study are available from the corresponding author on reasonable request.

\section{Ethics approval and consent to participate}

This study was approved by our institutional review board. Written informed consent was obtained from the patients for publication of this case series and accompanying images.

\section{Competing interests}

The authors declare that they have no competing interests.

Received: 15 August 2019 Accepted: 12 November 2019

Published online: 01 January 2020

\section{References}

1. Jauregui JJ, Cherian JJ, Pierce TP, Beaver WB, Issa K, Mont MA (2015) Longterm survivorship and clinical outcomes following total knee arthroplasty. J Arthroplast 30:2164-2166

2. Shan L, Shan B, Suzuki A, Nouh F, Saxena A (2015) Intermediate and longterm quality of life after total knee replacement. a systematic review and meta-analysis. J Bone Joint Surgery Am 97:156-168

3. Clement ND, Jenkins PJ, Brenkel IJ, Walmsley P (2012) Predictors of mortality after total knee replacement: A ten-year survivorship analysis. J Bone Joint Surg Br. 94:200-204

4. Kamaruzaman H, Kinghorn P, Oppong R (2017) Cost-effectiveness of surgical interventions for the management of osteoarthritis: a systematic review of the literature. BMC Musculoskelet Disord 18:183

5. Bourne RB, Chesworth BM, Davis AM, Mahomed NN, Charron KD (2010) Patient satisfaction after total knee arthroplasty: Who is satisfied and who is not? Clin Orthop Relat Res 468:57-63

6. Harmelink KEM, Zeegers AVCM, Hullegie W, Hoogeboom TJ, Nijhuis-van der Sanden MWG, Staal JB (2017) Are there prognostic factors for one-year outcome after total knee arthroplasty? A systematic review. J Arthroplasty 32:3840-53.e1

7. Lungu E, Vendittoli PA, Desmeules F (2016) Preoperative determinants of patient-reported pain and physical function levels following total knee arthroplasty: a systematic review. Open Orthop J 10:213-231

8. Wilson MD, Dowsey MM, Spelman T, Choong PF (2016) Impact of surgical experience on outcomes in total joint arthroplasties. ANZ J Surg 86:967-972

9. Palan J, Gulati A, Andrew JG, Murray DW, Beard DJ, EPOS study group (2009) The trainer, the trainee and the surgeons' assistant: clinical outcomes following total hip replacement. J Bone Joint Surg Br. 91:92834

10. Roidis N, Avramidis G, Kalampounias P, Karachalios TL. Long Term Clinical Outcome of Total Knee Arthroplasty. The Effect of Surgeon Training and Experience. Total knee arthroplasty. Long term outcome: Springer-Verlag London; 2015. P79-84

11. Mahaluxmivala J, Bankes MJ, Nicolai P. Aldam CH, Allen PW (2001) The effect of surgeon experience on component positioning in 673 press fit condylar posterior cruciate-sacrificing total knee arthroplasties. J Arthroplast 16:635-640

12. Whiteside LA, Arima J (1995) The anteroposterior axis for femoral rotational alignment in valgus total knee arthroplasty. Clin Orthop Relat Res 321:168-172

13. Akagi M, Oh M, Nonaka T, Tsujimoto H, Asano T, Hamanishi C (2004) An anteroposterior axis of the tibia for total knee arthroplasty. Clin Orthop Relat Res 420:213-219

14. Matziolis G, Krocker D, Weiss U, Tohtz S, Perka C (2007) A prospective, randomized study of computer-assisted and conventional total knee arthroplasty: Three-dimensional evaluation of implant alignment and rotation. J Bone Joint Surg Am 89:236-243

15. Wei MH, Lin YL, Shi HY, Chiu HC (2010) Effects of provider patient volume and comorbidity on clinical and economic outcomes for total knee arthroplasty. A population-based study. J Arthroplast 25:906-912

16. Kreder HJ, Grosso P, Williams JI, Jaglal S, Axcell T, Wal EK, Stephen DJ (2003) Provider volume and other predictors of outcome after total knee arthroplasty: a population study in Ontario. Can J Surg 46:15-22

17. Paterson JM, Williams Jl, Kreder HJ, Mahomed NN, Gunraj N, Wang X, Laupacis A (2010) Provider volumes and early outcomes of primary total joint replacement in Ontario. Can J Surg 53:175-183

18. Pritchett JW (2011) Patients prefer a bicruciate-retaining or the medial pivot total knee prosthesis. J Arthroplast 26:224-228

19. Beattie N, Maempel JF, Roberts S, Waterson HB, Brown G, Brenkel IJ, Walmsley PJ (2018) Surgery performed by supervised registrars does not adversely affect medium-term functional outcomes after total knee replacement. Ann R Coll Surg Engl 100:57-62

20. Bao MH, Keeney BJ, Moschetti WE, Paddock NG, Jevsevar DS (2018) Resident participation is not associated with worse outcomes after TKA. Clin Orthop Relat Res 476:1375-1390 
21. Weber M, Worlicek M, Voellner F, Woerner M, Benditz A, Weber D, Grifka J, Renkawitz T (2018) Surgical training does not affect operative time and outcome in total knee arthroplasty. PLoS One 13:e0197850

22. Khakha RS, Chowdhry M, Sivaprakasam M, Kheiran A, Chauhan SK (2015)

Radiological and functional outcomes in computer assisted total knee arthroplasty between consultants and trainees - a prospective randomized controlled trial. J Arthroplast 30:1344-1347

23. Berend ME, Ritter MA, Meding JB, Faris PM, Keating EM, Redelman R, Faris GW, Davis KE (2004) Tibial component failure mechanisms in total knee arthroplasty. Clin Orthop Relat Res 428:26-34

24. Sikorski JM (2008) Alignment in total knee replacement. J Bone Joint Surg Br 90:1121-1127

25. Barrack RL, Schrader T, Bertot AJ, Wolfe MW, Myers L (2001) Component rotation and anterior knee pain after total knee arthroplasty. Clin Orthop Relat Res 392:46-55

26. Huang NF, Dowsey MM, Ee E, Stoney JD, Babazadeh S, Choong PF (2012) Coronal alignment correlates with outcome after total knee arthroplasty. Fiveyear follow-up of a randomized controlled trial. J Arthroplast 27:1737-1741

\section{Publisher's Note}

Springer Nature remains neutral with regard to jurisdictional claims in published maps and institutional affiliations.

Ready to submit your research? Choose BMC and benefit from:

- fast, convenient online submission

- thorough peer review by experienced researchers in your field

- rapid publication on acceptance

- support for research data, including large and complex data types

- gold Open Access which fosters wider collaboration and increased citations

- maximum visibility for your research: over $100 \mathrm{M}$ website views per year

At BMC, research is always in progress.

Learn more biomedcentral.com/submissions 